\title{
The bluefish Pomatomus saltatrix (Pisces: Pomatomidae) in the Adriatic and Tyrrhenian Seas, can we call it climate invader?
}

\author{
Azzurro E. ${ }^{12} \quad$ Cerri J. ${ }^{3}$ \\ ${ }^{1}$ CNR-IRBIM, Largo Fiera della Pesca, 2, 60125 Ancona, Italy \\ ${ }^{2}$ Stazione Zoologica Anthon Dohrn, Naples, Italy \\ ${ }^{3}$ ISPRA, Institute for Environmental Protection and Research, Via del Cedro 57122, Livorno, Italy \\ January 28,2020
}

\begin{abstract}
Here, we investigate the recent spatio-temporal dynamics of the bluefish Pomatomus saltatrix, a warm water species, which is considered to have conquered the northern Mediterranean coasts due to climate warming. Capitalizing two independent surveys carried out through online questionnaires and vis-à-vis interviews, we accessed the ecological knowledge of 640 recreational fishers, and 206 small-scale fishers, respectively. Respondents provided coherent evidence of a rapid northward expansion of the bluefish along the Tyrrhenian and Adriatic Seas at an estimated speed of 0.8-1.4 degrees of latitude per year. Most fishers in the two seas believed the bluefish to negatively affect both fishing activities and the environment, just as if it was an invasive species and this negative perception was positively correlated with increasing bluefish abundances. The phenomenological effects of this widespread outbreak can be assimilated to a large invasion across various sectors of the Mediterranean Sea, posing the urgency of manage this issue and better understanding its linkage to climate drivers.
\end{abstract}

native invader | Mediterranean | Poleward migration | Climate change | recreational fishery | Pomatomus saltatrix

Correspondence: jacopo.cerri@isprambiente.it

CAUTION

The following manuscript is a preprint: it has not been peer-reviewed yet. We shared it to maximize its accessibility, as well as to increase the transparency of the review process, and suggestions will be appreciated. But this is not a peer-reviewed study. If you do not know what a preprint is, we encourage you to read this page: https://help.osf.io/hc/en-us/articles/ 360019930493-Preprint-FAQs\#what_is_a_preprint.

\section{Introduction}

Native species can occasionally outbreak causing negative impacts within their native range and this invasive potential has recently started to be considered in bio-invasion research. Indeed, even if the most of the problematic invasions are related to species translocated across vast distances (Simberloff et al., 2013; Ricciardi et al., 2017; Wilson et al. 2009), also native species can be capable of such behaviour, growing suddenly in abundance and dramatically expanding their distribution. These species, which become 'invasive' in their own native range, have been recently defined as 'native invaders' (Simberloff, 2011; Carey et al. 2012) and their emergence is usually provoked by human-related environmental changes, which might release a native species from a degree of previous control (Carey et al., 2012). The final outcome is the population outbreak, which can be completely analogous to exotic bioinvasions (Simberloff, 2011; Nackley et al., 2017; Blakburn et al., 2019). A particularly striking example of environmental change is global warming, which is driving changes in the physical and chemical properties of the ocean causing shifts in distribution to higher latitudes and to deeper locations, advances in spring phenology, declines in calcification, and increases in the abundance of warm-water species (Walther et al., 2002; Poloczanska et al., 2016). In turn, these transformations are expected to trigger dramatic ecosystem changes, which may be associated with profound socio-economic impacts (Pinsky et al., 2018; Pörtner and Peck, 2010). Mobile and migratory species are among the best documented cases, since they provide the most rapid responses to climatic fluctuations (Walther et al., 2002), with poleward movements widely documented in the world oceans (Stebbing et al., 2002; Perry et al., 2005; Booth et al., 2011; Fossheim et al., 2015), including the Mediterranean Sea (e.g. Azzurro, 2008, 2019a,b; Albouy et al., 2013).

The bluefish Pomatomus saltatrix is a widely distributed species, found in temperate and tropical marine waters throughout the world, except in the eastern Pacific (Juanes et al., 1996). It is also a migratory coastal pelagic fish, which supports a major recreational fishery in the North Western Atlantic and in other parts of the word, including large areas of the Mediterranean Sea (Pranovi et al. 2016). Its entire life cycle, including larval survival and seasonal migrations is closely linked to water temperature, which represents a strong limit for the distribution of this species (Fahay et al., 1999; Muelbert and Sinque, 1996). The bluefish is a native species for the Mediterranean Sea (Fisher et al., 1987), even if its occurrence was historically restricted to the southern and eastern sectors of the basin (Tortonese, 1986). Yet, in the last decades $P$. saltatrix started to be observed northward with respect to its usual range limits (e.g. Dulčić et al., 2005; Contreras-Balderas et al., 2002), being this geographical expansion explained as a likely consequence of increasing water temperatures (Sabates at al., 2012). Yet, so far the distribution dynamics of this species have been mostly documented through occasional observations (see Azzurro et al., 2008 for revision) and on local temporal series (Sabates et al., 1993; Villegas-Hernández, 2015), but a large-scale assessment of this phenomenon is still missing. In this study, we performed a large-scale survey, accessing the knowledge of recreational fishers operating in the Adriatic and Tyrrhenian 
seas. These Mediterranean sub-regions recently underwent a rapid and severe increase in water temperatures, with peaks of $0.16^{\circ} \mathrm{C} \mathrm{yr}-1$ during the period $1985-2006$ (Nykjaer, 2009). In the last decade, the spatio-temporal dimensions of species movements have been increasingly investigated with the help of local fishers (e.g. Delaney et al., 2008; Chandler et al., 2017; Azzurro et al., 2019a,b) and some information is also available for the bluefish (Silvano and Begossi, 2005; Brodie et al., 2018), though limited to the small spatial scale. We therefore accessed the ecological knowledge of Italian, Croatian and Montenegrin fishers aiming at: i) tracing back the spatio-temporal dynamics of the bluefish geographical expansion in the northern sectors of the Mediterranean Sea and ii) assessing how do fishers perceive this species in relation to the natural environment and to their own fishing activities. Finally, we evaluated the coherence of the respondent's perceptions among different areas, comparing our findings with the outcomes of an independently generated dataset.

\section{Methods}

The online questionnaire. This study was based on an archived dataset, containing the answers to an online questionnaire that had been previously administered to recreational fishers in Italy and Croatia (Cerri et al., 2019). The online questionnaire was designed with Google Forms (https://docs.google.com/forms), and an invitation link was shared on Facebook on the most important recreational fishing groups in Italy and Croatia. Only the most relevant groups were used, hosting a community ranging from 899 to 13.144 members. The online questionnaire contained 63 questions and it was divided into 7 different sections (Cerri et al., 2019). In the first section respondents provided information about their geographical location and their fishing activity. The second section focused on the bluefish (Pomatomus saltatrix): respondents were asked whether they had ever seen a bluefish, where, in which year, at which time of the year and at which depth. They also expressed their perceived abundance of the bluefish, from absent to dominant. In the Italian version respondents were also asked to rate the population trend of the bluefish over the last 10 years. Respondents were also asked to provide qualitative evaluation on the positive or negative impact of the bluefish on the environment and on fisheries. Finally, they were asked about their best catch of bluefish: the year, the gear adopted and the number of individuals that were fished. Similar questions were developed for the bluespotted cornetfish (Fistularia commersonii), the common dolphinfish (Coryphaena hippurus), the gray triggerfish (Balistes capriscus) and the Atlantic blue crab (Callinectes sapidus) (Cerri et al., in prep). In the last section, respondents were asked which species, among a list of north-expanding and invasive fish in the Mediterranean, they believed to have increased. Finally, they were also asked whether they saw or captured any new species they deemed to be exotic. We grouped observations from the Ionian and the Tyrrhenian Sea, as well as those from the Adriatic and the Ionian Sea, in two different groups, which will be hereafter referred as 'Tyrrhenian' and 'Adriatic' sectors, respec- tively. A complete copy of the questionnaire, altogether with the dataset, is available in Cerri et al. (2019).

The LEK dataset. To test for the robustness of our findings, we compared our online questionnaire with information extracted through vis-à-vis interviews with the local of fishers in the Tyrrhenian and Adriatic Sea (Azzurro et al., 2019a,b). These interviews represented a subsample of a larger panel covering nine different Mediterranean Countries, including 118 respondents from the Adriatic Sea (Italy, $\mathrm{n}=20$; Albania, $\mathrm{n}=25$; Montenegro, $\mathrm{n}=61$; Slovenia, $\mathrm{n}=12$ ) and 88 Italian respondents from the Tyrrhenian $(\mathrm{n}=76)$ and Ligurian $(n=12)$ Sea. The original study of Azzurro et al. (2019b) retrospectively elicited the temporal evolution of various fish species and we compared this information with the data of our online surveys, extracting information about the temporal evolution of the bluefish only. This dataset, hereafter referred as the 'LEK data', provided expert evaluations, mostly generated by interviews with small-scale fishers, of the abundance of bluefish across time up to the year 2016. Nevertheless, we selected the perceived abundances of 2015 as the most appropriate year for comparisons with our online survey collected in 2016-2018, being 'LEK data 2016' poorly represented in terms of completion rate (18.26\%). To triangulate our data about the first year when the species was recorded, we selected the first year when participants to the LEK studies reported the bluefish as being present in their area.

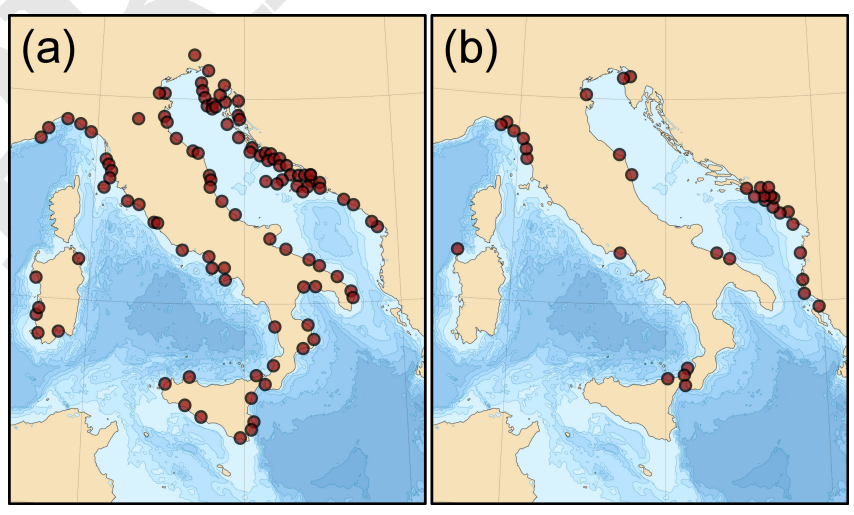

Fig. 1. Map of the study area: (a) locations of the online questionnaire $(N=792$ respondents extracted from Cerri et al., 2019) and (b) locations of the interviews from the LEK dataset ( $N=206$ respondents extracted from Azzurro et al. 2019).

Statistical analyses. To test for the effect of latitude over the perceived abundance of the bluefish, we fitted a multivariate linear regression using respondent's latitude as a predictor. To control for differences caused by respondents' location, a form of omitted variable bias, we added a dichotomous variable indicating whether respondents came from the Adriatic or the Tyrrhenian sector. This approach was used both for the data from the online questionnaire and for the LEK data. We selected a linear regression because the association between bluefish abundances and the latitude of respondents seemed to be linear. In the data from the online questionnaire we assumed a Normal distribution of the error, while in the LEK data we used a robust regression with 
a re-weighted least squares estimator, as perceived bluefish abundance showed a more skewed distribution.

To test for the existence of temporal lags in bluefish colonization between the Tyrrhenian and the Adriatic Sea, we compared respondents from these two areas in terms of the year when they had observed the bluefish for the first time. Furthermore, to obtain more detailed insights about the Adriatic Sea, we replicated the same analysis, by comparing respondents from Northern Adriatic, with respondents from Southern Adriatic.

We also inspected how respondents perceived the bluefish, by analysing two questions asking whether they deemed the bluefish to be "a positive thing" for the environment and for fisheries. Finally, we used a logistic regression to see if negative perceptions were associated to perceived bluefish abundances. For this type of analysis, we converted the two questions into two dichotomous variables, assuming a value of 1 when respondents did not believe the bluefish to be positive for the environment or fisheries, and 0 otherwise.

Statistical analysis was carried out with the statistical software R (R Core Team, 2018) and a reproducible software code is available in the supplementary information, altogether with the outputs of the fitted models.

\section{Results}

Characteristics of the sampled population. Overall, we collected a total of 792 filled in questionnaires (Cerri et al., 2019; Fig. 1) and, filtering out those respondents who never saw a bluefish $(n=132)$, we retained a final sample of 640 observations. Italian respondents accounted for $85.9 \%$ of the sample, whilst the remaining $14.06 \%$ were Croatian and Montenegrin. Respondents were almost equally distributed between the Tyrrhenian $(9.06 \%)$ and the Adriatic $(50.93 \%)$ sectors. Only 5 respondents were women. Most respondents started fishing after the 1980s, both in the Tyrrhenian $(75.44 \%)$ and in the Adriatic $(86.45 \%)$. Respondents were classified as spearfishers $(59.23 \%$ in the Tyrrhenian, $45.38 \%$ in the Adriatic), anglers (16.56\% in the Tyrrhenian, $20.85 \%$ in the Adriatic) or both (24.20\% in the Tyrrhenian, $33.74 \%$ in the Adriatic) (Fig.1). Respondents' age was similar between the Tyrrhenian $(18-20$ years $=6.68 \% ; 21-30$ years $=24.20 \%$; $31-40$ years $=23.56 \% ; 41-50$ years $=24.20 \% ; 51-60$ years $=$ $13.69 \% ; 61-70$ years $=4.58 \% ; 71-80$ years $=0.00 \%)$ and the Adriatic Sea $(18-20$ years $=6.60 \% ; 21-30$ years $=26.68 \%$; $31-40$ years $=31.28 \% ; 41-50$ years $=20.24 \% ; 51-60$ years $=$ $10.12 \% ; 61-70$ years $=1.53 \% ; 71-80$ years $=0.31 \%$ ).

Spatio-temporal insights. Overall, spearfishers, anglers and respondents practicing both, showed minor differences in the perceived abundance of the bluefish (Fig. 2). Perceived bluefish abundances were also similar between respondents from Italy and respondents from Croatia and Montenegro (Fig. 3).

Linear regression revealed a clear effect of respondent's latitude over the perceived abundance of the bluefish, with decreasing values towards northern areas (Fig. 4).

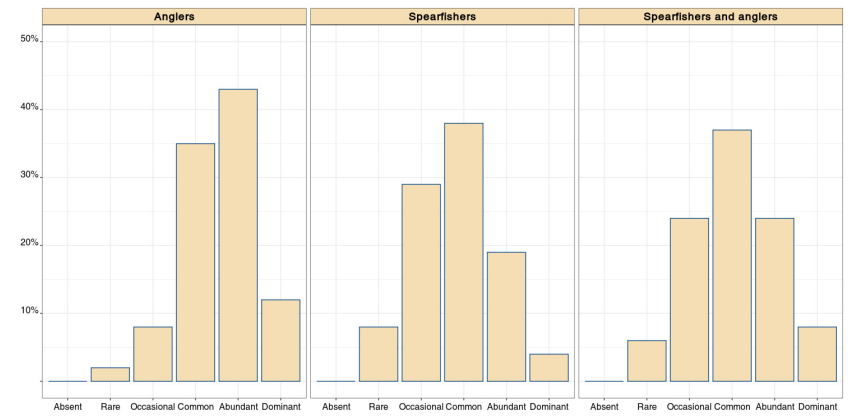

Fig. 2. Perceived abundance of the bluefish between different groups of respondents from the online questionnaire: spearfishers, anglers and respondents who practiced both.

The year when respondents observed their first bluefish showed a temporal lag between the Tyrrhenian (median year = 2008) and the Adriatic Sea (median year = 2012) (Fig. 5). A similar lag occurred between the southernmost (median year $=2010)$ and the northernmost (median $=2014)$ edges of the Adriatic Sea. The LEK dataset provided a similar spatial gradient for the Adriatic sea, with first records in Northern Adriatic that were delayed in time, compared to those from Southern Adriatic: respondents from latitudes lower than 42 degrees had a median first observation around 2004, while respondents from latitudes greater than 45 degrees had a median first observation around 2010. Therefore, the species seems to have colonized the Adriatic Sea in a timespan of 47 years, with a pace of about 0.8 - 1.4 degrees of latitude per year, corresponding to, approximately, $90-160 \mathrm{~km}$ of latitude per year. We also highlighted a temporal delay of the bluefish expansion in the Tyrrhenian (median year $=2008)$ with respect to the Adriatic (median year $=2012)($ Fig. 5).

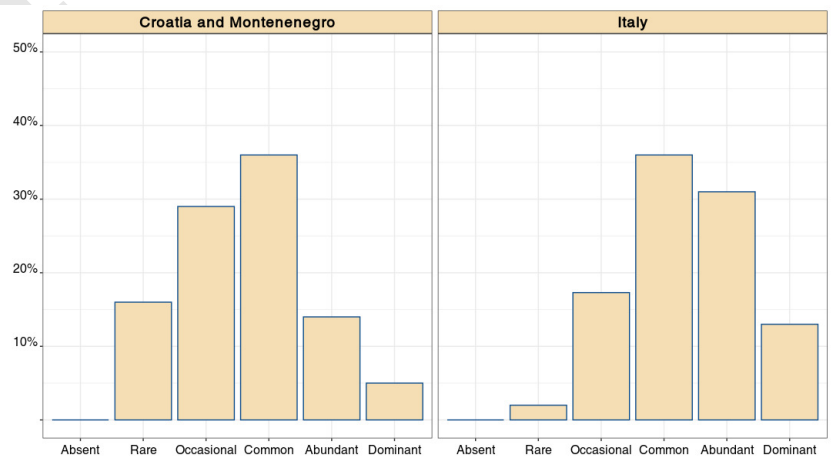

Fig. 3. Perceived abundance of the bluefish between respondents from Croatia and Montenegro, and respondents from Italy.

Perception of the bluefish impacts. A considerable portion of respondents declared that the bluefish was an undesirable novelty. Overall, 59.14\% of respondents believed it was negative for the environment and $55.32 \%$ for fisheries. In the Adriatic Sea, online questionnaires depicted negative perceptions for both the environment (Croatia and Montenegro $=63.33 \%$; Italy $=67.94 \%$ ) and fisheries (Croatia and Montenegro $=52.22 \%$; Italy $=65.53 \%)$. In Italy, values were critical on both Tyrrhenian (environment $=51.29 \%$; fisheries $=$ $45.56 \%$ ) and Adriatic Sea (environment $=67.94 \%$; fisheries 
$=65.53 \%)$.

Negative perceptions are also confirmed by the LEK dataset, when this information was collected. Respondents from Slovenia, Italy, Albania, Montenegro $(n=106)$ believed that the species was negative for the environment (overall = $82.07 \%$; Slovenia $=45.45 \%$; Italy $=90.47 \%$; Albania $=60 \%$; Montenegro $=91.52 \%)$ and for fisheries $(87.73 \%$; Slovenia $=45.45 \%$; Italy $=80.95 \%$; Albania $=100 \%$; Montenegro $=94.91 \%)$. Many respondents $(41.59 \%)$ reported that the bluefish has significant predatory impacts over target species (primarily mugilidae and the striped seabream Lithognathus mormyrus) and that it damages fishing gears (28.30\%). Overall, only few respondents $(n=9)$ had a contradictory perception of the species, believing that the bluefish was a positive thing for fisheries, although negative for the environment.

Interestingly, the negative perception about the potential impacts of the bluefish was associated with its perceived abundances: the logistic regression showed that believing the bluefish to be a negative thing for the environment, or for fisheries, became more and more likely as its perceived abundances increased (Fig. 6). This pattern was identical for the Tyrrhenian and the Adriatic Sea.

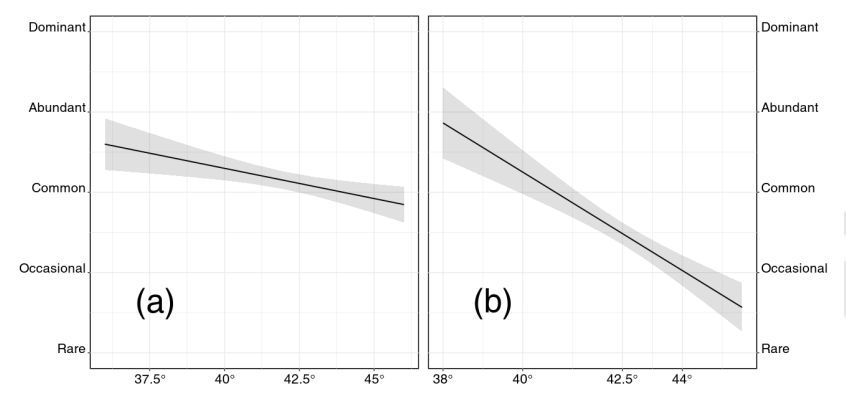

Fig. 4. Relationship between respondents' latitude and perceived abundance of the bluefish: findings from the linear regression with the data from the online survey (a) and from the LEK study (b).

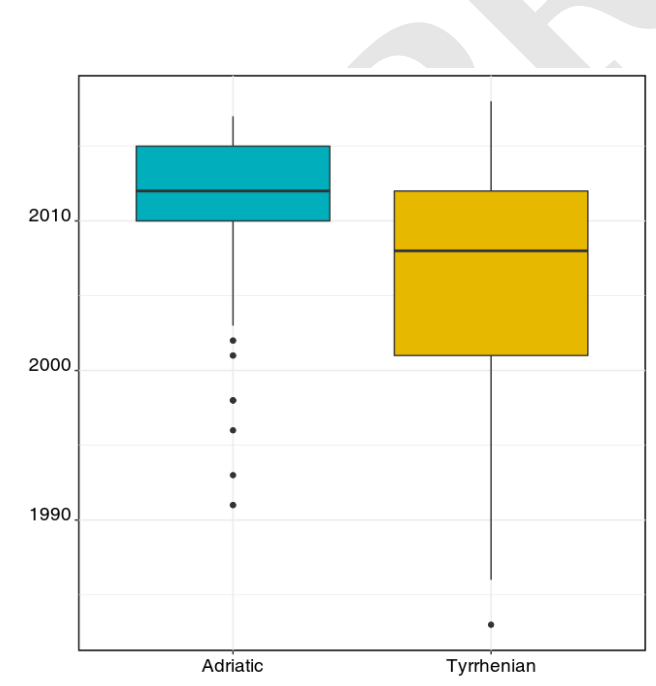

Fig. 5. Year when the bluefish was observed for the first time by respondents: results from the Adriatic and the Tyrrhenian sea.

\section{Discussion and conclusions}

Online surveys allowed us to access the knowledge of a widespread samples of observers, mapping large scale changes in the bluefish distribution. Notwithstanding the cultural and technical differences which may characterize recreational fishers across two different countries, varying latitudes and two marine sub-regions (Cowx, 2002), we found a high level of coherence on the information provided by the three groups of fishers. The widespread distribution of the respondents also allowed to investigate fine differences in the spatio-temporal dynamics between the Adriatic and Tyrrhenian sub-regions, attaining a spatial coverage which is rarely attained in LEK studies. Notwithstanding online surveys and the vis-à-vis interviews differed in their administration mode and targeted two different groups of respondents (recreational and small-scale fishers respectively), the concordance in their latitudinal patterns was remarkable. Their agreement was also coherent across fishers using different fishing gears. Briefly speaking, both, our data and the LEK survey told the same story: a rapid northward expansion of the bluefish across the Adriatic and Tyrrhenian coasts. This massive outbreak is also confirmed by huge quantities of the species that are occasionally captured in the study area. For example, exceptional captures of $1500 \mathrm{Kg}$ were realized by purse seiners operating along the Croatian coasts in January 2003 and 2019 (Dulčić et al., 2019) What the reasons behind such a great change? So far, a number of studies have linked the success of $P$. saltatrix to warming water conditions, especially in the NW Mediterranean. For example, Sabates (2012) observed that the occurrence of bluefish larvae in plankton was associated to increasing water temperatures in the NW; Villegas-Hernandez et al. (2015) demonstrate that the bluefish benefit from sea warming by increasing fish conditions, which would enhance population growth in these areas.

We must also consider the impressive speed of the $P$. saltatrix geographical expansion. Indeed, the species seems to have colonized the whole Adriatic Sea in a timespan of approximately 4-7 years, with a rate of 90-160 km of latitude per year or 0.8-1.4 degrees of latitude per year. This value is much higher than that experienced by other northward expanding species such as the Northeast Atlantic Mackerel (Scomber scombrus, Olafsdottir et al., 2018) or the blue whiting (Micromesistius poutassou, Fossheim, 2015) in the Nordic seas. Yet, interestingly, it falls within the range of speeds calculated for some invasive fishes in the Mediterranean Sea (Lasram et al., 2010). Due to the limits of our current knowledge, a causal attribution of climate change to the bluefish success remains highly possible but also speculative. Certainly, other factors, such as the role of trophic adaptability (Pottes et al., 2016), genetic changes due to contacts between previously isolated populations (e.g. Muelbert, and Sinque, 1996; Pardiñas et al., 2010) and community interactions needs to be integrated to provide a proper evaluation of bluefish response to climate change, as recently recognized by other similar studies (Walther et al., 2002; Gilman et al., 2010).

Whatever are the driving forces, the outbreak of $P$. saltatrix 

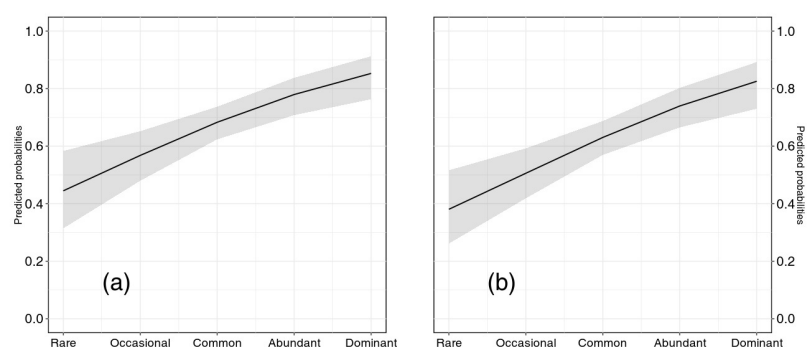

Fig. 6. Relationship between perceived bluefish abundance and perceived negative impacts over the marine environment (a) and over fisheries (b). Perceived negative impacts are represented through predicted probabilities for the dichotomous variable indicating whether respondents believed the bluefish a negative thing for the environment/fisheries: the more abundant the bluefish, the higher the probability that this variable assumed a value of 1 .

is a palpable reality, which probably brings major, though undisclosed, ecological impacts. These are also the expected consequences of introducing a voracious predator (Buckel et al., 1999), which became suddenly abundant over large geographical areas. Noteworthy, $P$. saltatrix was perceived as negative novelty either for the environment and for the fishing activities, despite its value as a big game fish (Pranovi et al. 2016), Indeed, the perception of both Italian and Croatian fishers was overall negative, and this bad perception worsened along with increasing abundances of the species in the survey area. Evidently, the opportunity to target a new large fish does not compensate the associated negative effects perceived by the respondents. The bluefish is known to kill fish apparently far in excess of their feeding requirements (Collette, 1999) and this behaviour was perfectly noted by the most of the recreational fishers, which often declared that 'the bluefish is much fun to catch, but it literally destroys small fish, especially mullets'. Another very common statement, usually made by small-scale fishers was: 'the bluefish attacks the other preys and we do not know how to really catch it".

Other studies (e.g. Buckel et al., 1999) documented the negative impacts of $P$. saltatrix on coastal and estuarine fish as well as negative interactions with human activities (e.g. seacage farms) associated to economic losses (Sanchez-Jerez et al., 2008). Here for the first time, our findings would suggest that this species may be a problematic predator across large sectors of the Mediterranean Sea. In conclusion, we might consider that the rapid outbreak, geographical expansion and perceived ecological and socio-economical impacts of P. saltatrix, meets three of the fundamental criteria contributing to define a species as an invader (Simberloff, 2013). Even if the bluefish cannot be considered as such by the mostly adopted definitions (Occhipinti and Galil, 2014), it still may deeply interfere with community-level processes like predation, competition, facilitation, disturbance, which operate on populations, independently of their entry mode (Thompson et al., 1995). For these reasons, some authors (reviewed by Válery et al., 2008) have started to qualify species as invasive also when they colonizes and dominates a new adjacent or nearby habitat following diffusion dispersal (sensu
Thompson et al. 1995; Davis and Thompson 2000). Without entering in the terminology debate (Colautti and MacIsaac, 2004), we just realized that this broader and more pragmatic notion of biological invasion better apply to our case, which describes the phenomenological (from Greek, phainen, 'to appear') evidence of a P. saltatrix outbreak across the Adriatic and Tyrrhenian coasts. Now, following the logic of a phenomenon "appearing as such" (Husserl 1913) and taking into appropriate account the plausible role of climate changes (Sabates et al., 1993; Villegas-Hernández, 2015) we might wonder if the bluefish be regarded be as a 'climate invader'. Quite surprisingly, despite the recognized positive interaction between raising temperatures and successful invasions (Stachowicz et al., 2002), the idea that climate change itself could be the cause of an invasion hasn't received much attention (Nackley et al., 2017). Future studies could possibly clarify this aspect, taking into appropriate account all the possible drivers, which may be involved in weakening the natural obstacles to the bluefish proliferation. Acknowledging this potential would contribute to a deeper understanding of the biotic transformations occurring across our warming oceans and to better inform policy and adaptive management of native range expansions.

\section{ACKNOWLEDGEMENTS}

This study has been partially supported by the Interreg Med Programme (Project MPA-Adapt - Grant number 1197 | 1MED15_3.2_M2_337 and Project MPAENGAGE - grant number: 5216 | 5MED18_3.2_M23_007). We warmly acknowledge all the researchers and fishers, which contributed to the process of data generation through online questionnaires (http://doi.org/10.5281/) and vis-à-vis interviews (https://zenodo.org/record/ S3W5p8). We also acknowledge the contribution of the programs CIESM Tropical Signals (funded by the Albert II of Monaco Foundation), FAO-AdriaMed, and FAO-MedSudMed.

\section{References}

Albouy C, Guilhaumon F, Leprieur F, Lasram FBR, Somot S, Aznar R, Velez L, Le Loch F, Mouillot D (2013) Projected climate change and the changing biogeography of coastal Mediterranean fishes. J Biogeogr 40: 534-547. https://doi.org/10.1111/jbi.12013

Azzurro E, Bolognini L, Dragičević B, Drakulović D, Dulčić J, Fanelli E, Grati F, Kolitari J, Lipej L, Magaletti E, Marković O, Matić-Skoko S, Mavrić B, Milone N, Joksimović A, Tomanić J, Scarpato A, Tutman P, Vrdoljak D, Zappacosta F (2019) Detecting the occurrence of indigenous and non-indigenous megafauna through fishermen knowledge: A complementary tool to coastal and port surveys. Mar Poll Bull 147: 229-236. https://doi.org/10.1016/j.marpolbul.2018.01.016

Azzurro E, Sbragaglia V, Cerri J, Bariche M, Bolognini L, Ben Souissi J, Busoni G, Coco S, Chryssanthi A, Fanelli E, Garrabou J, Gianni F, Grati F, Kolitari J, Letterio G, Lipej L, Mazzoldi C, Milone N, Pannacciulli F, Pešić A, Ghanem R, Samuel-Rhoads Y, Saponari L, Tomanic J, Eda Topçu N, Vargiu G, Moschella P (2019) Climate change, invasive species and the shifting distribution of Mediterranean fishes: a large scale assessment based on Local Ecological Knowledge. Glob Change Biol 25:2779-2792. https://doi.org/10.1111/gcb.14670

Azzurro, E., Commission Internationale pour l'Exploration Scientifique de la Mer Mediterranee- CIESM, Monaco. (2008, May). The advance of thermophilic fishes in the Mediterranean sea: overview and methodological questions. In CIESM workshop monographs (Vol. 35, pp. 39-45). CIESM, Monaco.

Blackburn TM, Bellard C, Ricciardi A (2019) Alien versus native species as drivers of recent extinctions. Front Ecol Environ 17: 203-207. https://doi.org/10.1002/fee.2020

Booth DJ, Bond N, Macreadie P (2011) Detecting range shifts among Australian fishes in response to climate change. Mar Freshwater Res 62: 1027-1042. https://doi.org/10.1071/MF10270 
Brodie S, Litherland L, Stewart J, Schilling HT, Pepperell JG, Suthers IM,(2018) Citizen science records describe the distribution and migratory behaviour of a piscivorous predator, Pomatomus saltatrix. ICES J Mar Sci 75, 1573-1582. https://doi.org/10.1093/icesjms/fsy057

Buckel JA, Conover DO, Steinberg ND, McKown KA (1999) Impact of age-0 bluefish (Pomatomus saltatrix) predation on age- 0 fishes in the Hudson River estuary: evidence for density-dependent loss of juvenile striped bass (Morone saxatilis). Can J Fish Aquat Sci 56: 275-287. https://doi.org/10.1139/f98-173

Buckel JA, Fogarty MJ, Conover DO (1999) Mutual prey of fish and humans: A comparison of biomass consumed by bluefish, Pomatomus saltatrix, with that harvested by fisheries. Fishery bulletin (Washington, DC) 97: 776-785.

Cerri J, Bolognini L, Dragičević B, Grati F, Sbragaglia V, Dulčić J, Azzurro E (2019) Poleward expanding species and non-indigenous species along the Italian, Croatian and Montenegrin coasts: a largescale survey based on online questionnaires. [Data set]. Zenodo. http://doi.org/10.5281/zenodo.3588353

Carey MP, Sanderson BL, Barnas KA, Olden JD (2012) Native invaders: challenges for science, management, policy, and society. Front Ecol Environ 10: 373-381. https://doi.org/10.1890/110060

Chandler M, See L, Copas K, Bonde AM, López BC, Danielsen F, Legind JK, Masinde S, Miller-Rushing AJ, Newman G, Rosemartin A, Turak E (2017) Contribution of citizen science towards international biodiversity monitoring. BiolConser 213: 280-294. https://doi.org/10.1016/j.biocon.2016.09.004

Colautti RI, MacIsaac HJ (2004) A neutral terminology to define 'invasive' species. Divers Distrib 10: 135-141. https://doi.org/10.1111/j.13669516.2004.00061.x

Collette BB. 1999. Pomatomidae. Bluefishes. In: Carpenter KE, Niem V (Eds.), FAO Species Identification Guide for Fishery Purposes, Vol. 4, p. 2650. Bony fishes part 2 (Mugilidae to Carangidae).

Contreras-Balderas S, Edwards RJ, Lozano-Vilano M, GarcíaRamírez M (2002) Fish biodiversity changes in the Lower Rio Grande/Rio Bravo, 1953-1996. Rev Fish Bio. Fisher 12: 219-240. https://doi.org/10.1023/A:1025048106849

Cowx, I. G. (2002). Recreational fishing. Handbook of fish biology and fisheries, 367-390. https://doi.org/10.1002/9780470693919.ch17

Davis MA, Thompson K (2000) Eight ways to be a colonizer; two ways to be an invader: a proposed nomenclature scheme for invasion ecology. Bull Ecol Soc Am 81: 226-230. https://www.jstor.org/stable/20168448

Delaney DG, Sperling CD, Adams CS, Leung B (2008) Marine invasive species: validation of citizen science and implications for national monitoring networks. Biol Invasions 10: 117-128. https://doi.org/10.1007/s10530007-9114-0

Dulčić J, Kraljević M, Pallaoro A, Glamuzina B (2005) Unusual catch of blurfish Pomatomus saltatrix (Pomatomidae) in Tarsko cove (northern Adiatic). Cybium 29: 207-208.

Dulčić J, Dragicevic B, Matic-Skoko S., Pavicic M., Vrdoljak D. Bluefish (Pomatomus saltatrix) again in the fishing catches in the northern Adriatic. 42nd CIESM congress, cascais Portugal 7-11 October 2019. http://ciesm.org/marine/congresses/sessions ${ }_{c}$ ascais.phpthur sday 27

Fisher, W., Bauchot, M.L., Schneider, M., 1987. Fiche FAO d'identification des especes pour les besoins de la peche. Rev. 1.. Mediterrane e et Mer Noire Zone de peche 37.. FAO Project GCPrINTr422rEEC, $1529 \mathrm{pp}$.

Fahay MP, Berrien PL, Johnson DL, Morse WW, Bluefish, Pomatomus saltatrix, life history and habitat characteristics , 1999NOAA Technical Memorandum, NMFS-NE-144pg. 68 pp

Fisher W, Bauchot ML, Schneider M (1987) Fiche FAO d'identification des especes pour les besoins de la peche. ZRev. 1.. Mediter-rane e et Mer Noire ZZone de peche 37.. FAO Project GCPrINTr422rEEC, 1529 pp.

Fossheim M, Primicerio R, Johannesen E, Ingvaldsen RB, Aschan MM, Dolgov AV (2015). Recent warming leads to a rapid borealization of fish communities in the Arctic. Nat Clim Change 5: 673. https://doi.org/10.1038/nclimate2647

Gilman SE, Urban MC, Tewksbury J, Gilchrist GW, Holt RD (2010) A framework for community interactions under climate change. Trends Ecol Evol 25: 325-331. https://doi.org/10.1016/j.tree.2010.03.002

Juanes F, Hare JA, Miskiewicz AG (1996) Comparing early life history strategies of Pomatomus saltatrix: a global approach. Mar Freshwater Res 47: 365-379. https://doi.org/10.1071/MF9960365
Husserl, E. (1913). Ideas pertaining to a pure phenomenology and to a phenomenological philosophy: First book: General introduction to a pure phenomenology. The Hague: Nijhoff 1982 (= Ideas).

Lasram FBR, Guilhaumon F, Mouillot D (2010) Global warming and exotic fishes in the Mediterranean Sea: introduction dynamic, range expansion and spatial congruence with endemic species. Fish Invasions of the Mediterranean Sea: Change and Renewal, 35-56.

Muelbert JH, Sinque C (1996) Distribution of bluefish (Pomatomus saltatrix) larvae along the continental shelf off southern Brazil. Mar Freshwater Res 47: 311-314. https://doi.org/10.1071/MF9960311

Nackley LL, West AG, Skowno AL, Bond W (2017) The nebulous ecology of native invasions. TrendsEcol Evol 32: 814-824. https://doi.org/10.1016/j.tree.2017.08.003

Nykjaer L (2009). Mediterranean Sea surface warming 1985-2006. Clim Res 39: 11-17. https://doi.org/10.3354/cr00794

Occhipinti-Ambrogi A, Galil BS (2004). A uniform terminology on bioinvasions: a chimera or an operative tool?. Mar Pollut Bull, 49: 688694. https://doi.org/10.1016/j.marpolbul.2004.08.011

Olafsdottir AH, Utne KR, Jacobsen JA, Jansen T, Óskarsson GJ, Nøttestad L, Elvarsson BP, Broms C, Slotte A (2019) Geographical expansion of Northeast Atlantic mackerel (Scomber scombrus) in the Nordic Seas from 2007 to 2016 was primarily driven by stock size and constrained by low temperatures. Deep Sea Research Part II: Topical Studies in Oceanography, 159, 152-168. https://doi.org/10.1016/j.dsr2.2018.05.023

Pardiñas AF, Campo D, Pola IG, Miralles L, Juanes F, Garcia-Vazquez E. (2010). Climate change and oceanic barriers: genetic differentiation in Pomatomus saltatrix (Pisces: Pomatomidae) in the North Atlantic Ocean and the Mediterranean Sea. J Fish Biol 77: 1993-1998. https://doi.org/10.1111/j.1095-8649.2010.02774.x

Parmesan C, Ryrholm N, Stefanescu C, Hill JK, Thomas CD, Descimon H, Huntley B, Kaila L, Kullberg J, Tammaru R, Tennent WJ, Thomas JA, Warren, M (1999) Poleward shifts in geographical ranges of butterfly species associated with regional warming. Nature 399: 579. https://doi.org/10.1038/21181

Perry AL, Low PJ, Ellis JR, Reynolds JD (2005) Climate change and distribution shifts in marine fishes. Science 308: 1912-1915. DOI: 10.1126/science. 1111322

Poloczanska ES, Burrows MT, Brown CJ, García Molinos J, Halpern BS, Hoegh-Guldberg O, Kappel CV, Moore PJ, Richardson AJ, Schoeman DS, Sydeman WJ (2016) Responses of marine organisms to climate change across oceans. Front Mar Sci 3: 62. https://doi.org/10.3389/fmars.2016.00062

Pörtner HO, Peck MA (2010). Climate change effects on fishes and fisheries: towards a cause-and-effect understanding. J Fish Biol 77: 1745-1779. https://doi.org/10.1111/j.1095-8649.2010.02783.x

Potts WM., Bealey RSJ,Childs AR (2016) Assessing trophic adaptability is critical for understanding the response of predatory fishes to climate change: a case study of Pomatomus saltatrix in a global hotspot, Afr J Mar Sci 38: 539-547, DOI: 10.2989/1814232X.2016.1249027.

Pranovi F, Monti MA, Caccin A, Colla S, Zucchetta M (2016) Recreational fishing on the West coast of the Northern Adriatic Sea (Western Mediterranean) and its possible ecological implications. Regional Studies in Marine Science 3: 273-278. https://doi.org/10.1016/j.rsma.2015.11.013

R Core Team (2014). R: A language and environment for statistical computing. R Foundation for Statistical Computing, Vienna, Austria. URL http://www.R-project.org/

Ricciardi A, Blackburn TM, Carlton JT, Dick JT, Hulme PE, Iacarella JC, Jeschke JM, Liebhold AM, Lockwood J, MacIsaac H, Pyšek P, Richardson DM, Ruiz GM, Simberloff D, Sutherland WJ, Wardle DA, Aldrigde DC (2017) Invasion science: a horizon scan of emerging challenges and opportunities. Trends Ecol Evol 32: 464-474. https://doi.org/10.1016/j.tree.2017.03.007

Sabatés A, Martin P (1993) Spawning and distribution of bluefish Pomatomus saltatrix (L.) in the northwestern Mediterranean. J Fish Biol 42: 109-118. https://doi.org/10.1111/j.1095- 8649.1993.tb00309.x

Sabatés A, Martín P, Raya V (2012) Changes in life-history traits in relation to climate change: bluefish (Pomatomus saltatrix) in the north- western Mediterranean. ICES J Mar Sci 69: 1000-1009. https://doi.org/10.1093/icesjms/fss053

Sanchez-Jerez P, Fernandez-Jover D, Bayle-Sempere J, Valle C, Dempster T, Tuya F, Juanes F (2008) Interactions between bluefish Pomatomus 
saltatrix (L.) and coastal sea-cage farms in the Mediterranean Sea. Aquaculture 282: 61-67. https://doi.org/10.1016/j.aquaculture.2008.06.025

Simberloff D, Martin JL, Genovesi P, Maris V, Wardle DA, Aronson J, Courchamp F, Galil B, García-Berthou E, Pascal M, Pyšek P, Sousa R, Tabacchi E, Vilà M (2013) Impacts of biological invasions: what's what and the way forward. Trends Ecol Evol 28: 58-66. https://doi.org/10.1016/j.tree.2012.07.013

Simberloff D (2011). Native invaders. - In: Simberloff, D. and Rejmanek, M. (eds), Encyclopedia of biological invasions. Univ. of California Press, pp. 472-475.

Silvano RA, Begossi A (2005) Local knowledge on a cosmopolitan fish: ethnoecology of Pomatomus saltatrix (Pomatomidae) in Brazil and Australia. Fish Res 71: 43-59. https://doi.org/10.1016/j.fishres.2004.07.007

Stachowicz JJ, Terwin JR, Whitlatch RB, Osman RW (2002) Linking climate change and biological invasions: ocean warming facilitates nonindigenous species invasions. PNAS, 99: 15497-15500. 15497-15500. https://doi.org/10.1073/pnas.242437499

Stebbing ARD, Turk SMT, Wheeler A, Clarke KR (2002) Immigration of southern fish species to south-west England linked to warming of the North Atlantic (1960-2001). J Mar Biol Assoc UK 82: 177-180. https://doi.org/10.1017/S0025315402005325

Thompson K, Hodgson JG, Rich TC (1995) Native and alien invasive plants: more of the same? Ecography, 18: 390-402. https://doi.org/10.1111/j.1600-0587.1995.tb00142.x

Tortonese E. Whitehead PJP, Bauchot ML, Hureau JC, Nielsen J, Tortonese E. Pomatomidae, Fishes of the Northeastern Atlantic and Mediterranean, 11, 1986ParisUNESCO(pg. 812-813)

Valéry L, Fritz H, Lefeuvre JC, Simberloff D (2009) Invasive species can also be native.... Trends Ecol Evolution 24: 585. https://doi.org/10.1016/j.tree.2009.07.003

Villegas-Hernández H, Lloret J, Muñoz M (2015) Reproduction, condition and abundance of the Mediterranean bluefish (Pomatomus saltatrix) in the context of sea warming. Fish Oceanogr 24: 42-56. https://doi.org/10.1111/fog. 12091

Walther GR, Post E, Convey P, Menzel A, Parmesan C, Beebee TJ, Fromentin JM, Hoegh-Guldberg, Barlein F (2002) Ecological responses to recent climate change. Nature, 416: 389. https://doi.org/10.1038/416389a

Wilson JR, Dormontt EE, Prentis PJ, Lowe AJ, Richardson DM (2009) Something in the way you move: dispersal pathways affect invasion success. Trends Ecol Evol 24: 136-144. https://doi.org/10.1016/j.tree.2008.10.007 